SHORT REPORT

\title{
Longitudinal analysis of the effect of apolipoprotein $E \epsilon 4$ and education on cognitive performance in elderly subjects: the PAQUID study
}

\author{
M Winnock, L Letenneur, H Jacqmin-Gadda, J Dallongeville, P Amouyel, J F Dartigues
}

J Neurol Neurosurg Psychiatry 2002;72:794-797

Background: The apolipoprotein $E$ (apoE) $\epsilon 4$ allele has been shown to be a risk factor for dementia, but it is not clear to what extent apoE affects overall cognitive function in non-demented elderly subjects, or how this risk may be modified by gene-environment interactions.

Objective: To examine changes in cognitive function in elderly people as a function of the apoE $\epsilon 4$ phenotype.

Methods: A community based prospective cohort study of 600 non-demented subjects aged over 65 years living in Gironde (France) was analysed to evaluate change over time (seven years) in scores on the mini-mental state examination (MMSE).

Results: Age at cohort inception was negatively associated with cognitive performance for both $\epsilon 4$ carriers and non-carriers $(p<0.001)$. The evolution of MMSE scores differed as a function of age: scores remained stable among younger subjects but decreased over time in older subjects. The $\epsilon 4$ allele was shown to be significantly associated with lower cognitive performance at baseline $(p=0.02)$. The course of cognitive performance during the follow up was the same for both $\epsilon 4$ carriers and non-carriers. Lower educational level was associated with lower cognitive performance at baseline $(p<0.001)$ and the effect of an $\epsilon 4$ allele on cognitive performance disappeared after adjustment for education. When incident cases of dementia were excluded, the results were unchanged except for the course of the MMSE scores, which now remained stable over time in the older subjects. Conclusions: apoE $\epsilon 4$ carriers show decreased MMSE scores compared with $\epsilon 4$ non-carriers, but the effect of apoE on cognition disappears after adjustment for education. Non-demented elderly people maintain a stable cognitive performance regardless of their apoE phenotype.

$\mathrm{T}$ he association between the $\epsilon 4$ allele of apolipoprotein $\mathrm{E}$ (apoE) and the risk of developing Alzheimer's disease is well established. The presence of one or two $\epsilon 4$ alleles is associated with both familial and sporadic late onset Alzheimer's disease in most ethnic groups, ${ }^{12345}$ across all ages, and in both men and women. ${ }^{6}$ On the other hand, the presence of the $\epsilon 2$ allele appears to have a protective effect. ${ }^{6}$

While there is overall consensus about the role of apoE as a risk factor for Alzheimer's disease, less is known about the influence of apoE on cognitive function. At present it is not clear whether the presence of the $\epsilon 4$ allele conveys a risk of cognitive impairment in elderly people without dementia.

Several longitudinal studies using the mini-mental state examination $(\mathrm{MMSE})^{8}$ have been planned to evaluate progression of cognitive decline in both demented and non-demented individuals. So far these have shown a clear decline in the former and relative stability in the latter. ${ }^{9011}$
Our objective in this study was to describe the relation between the presence of the apoE $\epsilon 4$ allele and changes in the MMSE score during a seven year period in a large sample of non-demented elderly people and to examine how environmental factors, such as education, might influence this relation.

\section{METHODS}

This study was part of the PAQUID research programme, a prospective cohort study of normal and pathological cerebral aging, composed of a randomly selected sample of noninstitutionalised individuals aged 65 years and over living in the south west of France. The methodology of this study has already been extensively described. ${ }^{12}$

The survey started in 1988, following 2792 subjects who were interviewed at home by trained psychologists at one, three, five, eight, and 10 years after the baseline visit. Our sample consisted of a subgroup of 626 subjects who volunteered to give a blood sample for apoE phenotyping at the first year follow up interview.

Cognitive performance was evaluated at each visit using a comprehensive battery of neuropsychological tests. After the psychometric evaluation, the psychologists systematically completed an evaluation of the DSMIII-R criteria for dementia, ${ }^{13}$ and subjects who met these criteria were then seen by a senior neurologist who confirmed the diagnosis of dementia.

The results presented here are based on the MMSE, which is a global mental function screening test. ${ }^{8}$ For the analyses we used longitudinal MMSE score data, obtained from the one, three, five, and eight year follow up interviews; the 10 year follow up interview was only used to obtain DSMIII-R data and to establish diagnosis of dementia.

Our objective was to investigate the evolution of cognitive performance in non-demented elderly individuals. Thus in the initial analysis we excluded those subjects with a confirmed diagnosis of dementia at baseline $(n=22)$, and also at the first year follow up $(n=4)$, as the blood sample was collected at that time. In a second analysis, we then excluded any subjects in whom a diagnosis of dementia had been made between the three year and the 10 year follow up visits $(n=53)$. In this way, we were certain that no subjects included in the second analysis had been diagnosed as having dementia in the two year period after the last MMSE score. The sample for the first analysis comprised 600 subjects and for the second analysis, 547 subjects.

Serum samples were obtained during the first year follow up (1989-90) and frozen until determination of apoE phenotype. Homozygotes and heterozygotes for apoE $\in 4$ were combined and designated as $\epsilon 4$ carriers; other phenotypes were designated as $\epsilon 4$ non-carriers.

\section{Statistical analyses}

To study the variables associated with cognitive performance, we used a random effects linear regression model, which takes 
Table 1 Results of linear regression with random effects for the square root of the number of errors in the mini-mental state examination (MMSE) for non-demented subjects at the one year follow up (A) and after exclusion of those diagnosed as demented on the one, three, five, eight, and 10 year follow up interviews (B)

\begin{tabular}{|c|c|c|c|c|c|c|c|c|c|c|c|c|}
\hline \multirow[b]{3}{*}{ Variable } & \multicolumn{6}{|c|}{$A(n=600)$} & \multicolumn{6}{|l|}{$B(n=547)$} \\
\hline & \multicolumn{3}{|l|}{ Model 1} & \multicolumn{3}{|l|}{ Model 2} & \multicolumn{3}{|l|}{ Model 1} & \multicolumn{3}{|l|}{ Model 2} \\
\hline & $\beta$ & SE & $\mathrm{p}$ Value & $\beta$ & SE & $\mathrm{p}$ Value & $\beta$ & SE & $\mathrm{p}$ Value & $\beta$ & SE & $\mathrm{p}$ Value \\
\hline Age (at baseline) & 0.045 & 0.005 & 0.0001 & 0.039 & 0.004 & 0.0001 & 0.042 & 0.005 & 0.0001 & 0.036 & 0.005 & 0.0001 \\
\hline Sex & -0.025 & 0.056 & 0.6534 & -0.085 & 0.051 & 0.0965 & -0.051 & 0.054 & 0.3444 & -0.107 & 0.050 & 0.0333 \\
\hline Time & -0.192 & 0.075 & 0.0100 & -0.190 & 0.074 & 0.0104 & 0.006 & 0.070 & 0.9280 & 0.008 & 0.070 & 0.9121 \\
\hline Age by time & 0.003 & 0.001 & 0.0057 & 0.003 & 0.001 & 0.0058 & -0.0002 & 0.001 & 0.8654 & -0.0002 & 0.001 & 0.8529 \\
\hline Apolipoprotein $E \in 4 \dagger$ & 0.155 & 0.068 & 0.0223 & 0.056 & 0.063 & 0.3715 & 0.156 & 0.066 & 0.0183 & 0.065 & 0.062 & 0.2953 \\
\hline Education $\ddagger$ & & & & -0.624 & 0.060 & 0.0001 & & & & -0.558 & 0.061 & 0.0001 \\
\hline
\end{tabular}

A negative coefficient indicates an increase in the mean MMSE score.

* $\mathrm{SE}$, standard error.

†One or two alleles $v$ none.

$\ddagger$ Primary school with diploma $v$ no school/primary school without diploma.

into account the lack of independence of a subject's measurements across time. ${ }^{14}$ This intrasubject correlation was modelled by two independent subject specific random effects: a random intercept and a random slope. Parameters were estimated by the maximum likelihood method using SAS statistical software (SAS/STAT computer program, SAS Institute Inc, Cary, North Carolina, 1999).

\section{RESULTS}

At baseline, the mean (SEM) age of the 600 participants was $73.7(0.26)$ years, range 65 to 94 . No difference was found between mean ages for $\epsilon 4$ carriers (73.1 (0.53) years, range 65 to 92 ) and $\epsilon 4$ non-carriers ( 73.9 (0.29) years, range 65 to 94 ) $(t=1.37, \mathrm{p}=0.17)$. There was no difference in sex between $\epsilon 4$ carriers and non-carriers (men/women: carriers, 57/73; non-carriers, 203/267).

The most frequent apoE phenotypes for the group were $\epsilon 3 / \epsilon 3(\mathrm{n}=403), \epsilon 3 / \epsilon 4(\mathrm{n}=114)$, and $\epsilon 2 / \epsilon 3(\mathrm{n}=60)$. Individuals homozygous for the $\epsilon 4$ or $\epsilon 2$ alleles, or with the $\epsilon 2 / \epsilon 4$ phenotype, were poorly represented $(n=5,7$, and 11 , respectively). In our sample, approximately one in five subjects was an $\epsilon 4$ carrier $(21.7 \%, 130 / 600)$, and this proportion remained stable throughout the eight year follow up.

Level of education differed among $\epsilon 4$ carriers and noncarriers: educational attainment (diploma from primary school (up to age 11 ) or higher) was much higher among $\epsilon 4$ non-carriers $(77 \%, 362 / 470)$ than among $\in 4$ carriers $(58 \%$, $76 / 130$ ) (odds ratio, $2.38 ; 95 \%$ confidence interval, 1.55 to 3.66; $\mathrm{p}<0.0001)$.

All subjects completed the MMSE at least once; 574 (95.7\%), $508(84.7 \%), 457(76.2 \%)$, and 364 (60.7\%) completed the MMSE at the one, three, five, and eight year follow up visits, respectively. Four MMSE measures were available in 332 participants $(55.3 \%)$, and $116(19.3 \%)$ died during follow up. There were no differences in the response patterns between $\epsilon 4$ carriers and $\epsilon 4$ non-carriers (data not shown).

Results of the linear regressions with random effects for the square root of the number of errors are presented in table 1. Three basic variables were included in all models: age, sex, and time (that is, the number of years after follow up, measuring the evolution of cognitive performance over time).

In table 1, model 1A shows that age at baseline was highly associated with the mean MMSE score $(p=0.0001)$ - that is, younger subjects obtained better scores at that time (fig lA). Variables time and age by time were also significant $(p=0.01$ and $p=0.006$, respectively), indicating that the evolution of MMSE scores differed depending on age: the scores remained stable in the younger subjects, but in older subjects they decreased over time (fig 1A). At baseline, $\epsilon 4$ carriers had a significantly lower MMSE score than $\epsilon 4$ non-carriers $(p=0.02)$.
A lower educational level was associated with lower performance at baseline $(\mathrm{p}<0.0001)($ model $2 \mathrm{~A})$, but the evolution of cognitive performance was the same over time for all levels of education (education by time, $\mathrm{p}=0.14$ ). This effect was the same for $\epsilon 4$ carriers and $\epsilon 4$ non-carriers (apoE $\epsilon 4$ by education, $p=0.26$ ). In contrast, the effect of the presence of an $\epsilon 4$ allele on baseline cognitive performance disappeared when adjusted for education (fig lB)

When subjects who were diagnosed as demented during the 10 year follow up were excluded from the analyses, the effect of age at baseline upon cognitive performance was still significant $(\mathrm{p}<0.0001)$ (table l, model lB) (fig lB). However, the evolution of cognitive performance over time, denoted as time, became non-significant, meaning that the level of performance remained stable over time. No differential evolution as a function of age at baseline was observed (age by time, $p=0.87$ ). The apoE $\epsilon 4$ allele was still important for cognitive performance, as $\epsilon 4$ carriers had a decreased score at baseline compared with non-carriers (model $1 \mathrm{~B})(\mathrm{p}=0.018)$ (fig 1B). Education continued to have a significant effect $(p<0.0001)$, and the influence of the presence of an $\epsilon 4$ allele again disappeared when adjusted for education (model 2B) (fig 1D). In contrast to model 1B, women showed a better performance at baseline than men $(\mathrm{p}=0.03)$ when cognitive performance was adjusted for education, but the evolution over time was the same for both sexes (sex by time, $\mathrm{p}=0.16$ ).

\section{DISCUSSION}

Four major conclusions can be drawn from this study. First, the apoE phenotype had a significant effect on cognitive performance of elderly subjects at the baseline level, in that apoE $\epsilon 4$ carriers had a decreased MMSE score compared with noncarriers. Second, the difference between $\epsilon 4$ carriers and non-carriers disappeared after adjustment for education. Third, no global cognitive decline was observed over time in elderly subjects, once those with dementia or impending dementia were excluded from the analysis; the slight decline in cognitive function observed when the analysis included the entire cohort reflected the decline in individuals who were in the early stages of dementia. Finally, the level of global cognitive performance remained stable throughout follow up and was independent of the apoE phenotype, suggesting that this phenotype did not influence cognitive performance over time.

The evoluation of MMSE scores depended on the subject's age at entry to the study and on educational level. Interestingly, the effect of apoE $\epsilon 4$ disappeared after taking into account the level of education. In our study, the frequency of subjects with a primary school diploma differed between $\epsilon 4$ carriers and $\epsilon 4$ non-carriers, suggesting that apoE phenotype might influence cognition through the entire life span. 


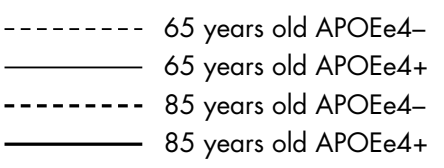

APOE $\varepsilon 4$ effect on cognitive performance
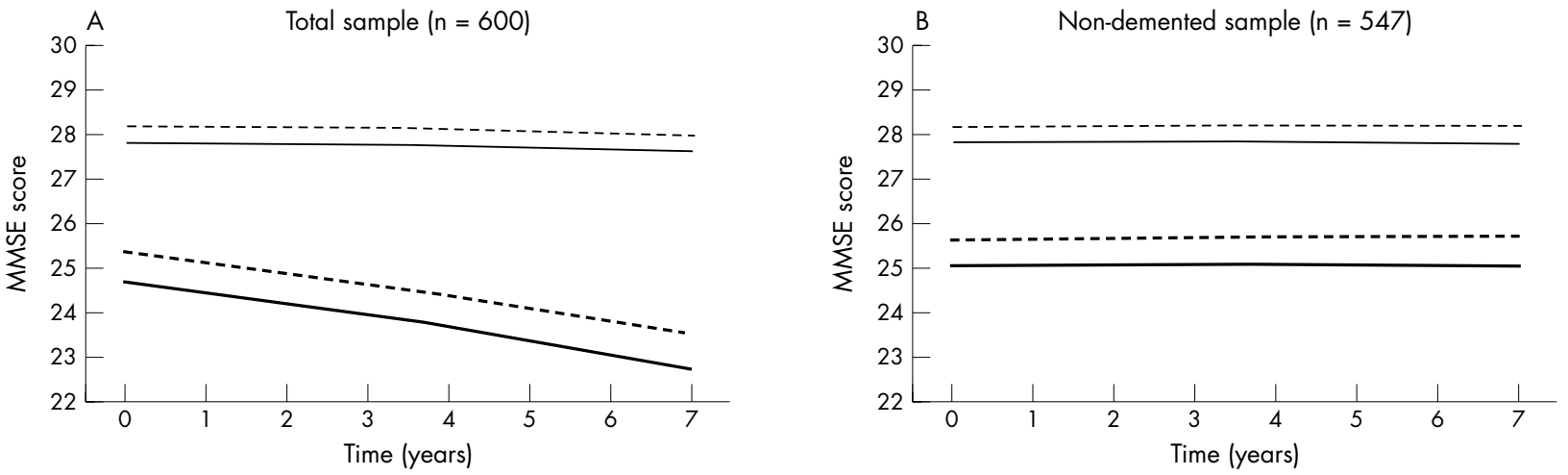

APOE $\varepsilon 4$ effect on cognitive performance after adjustment for education
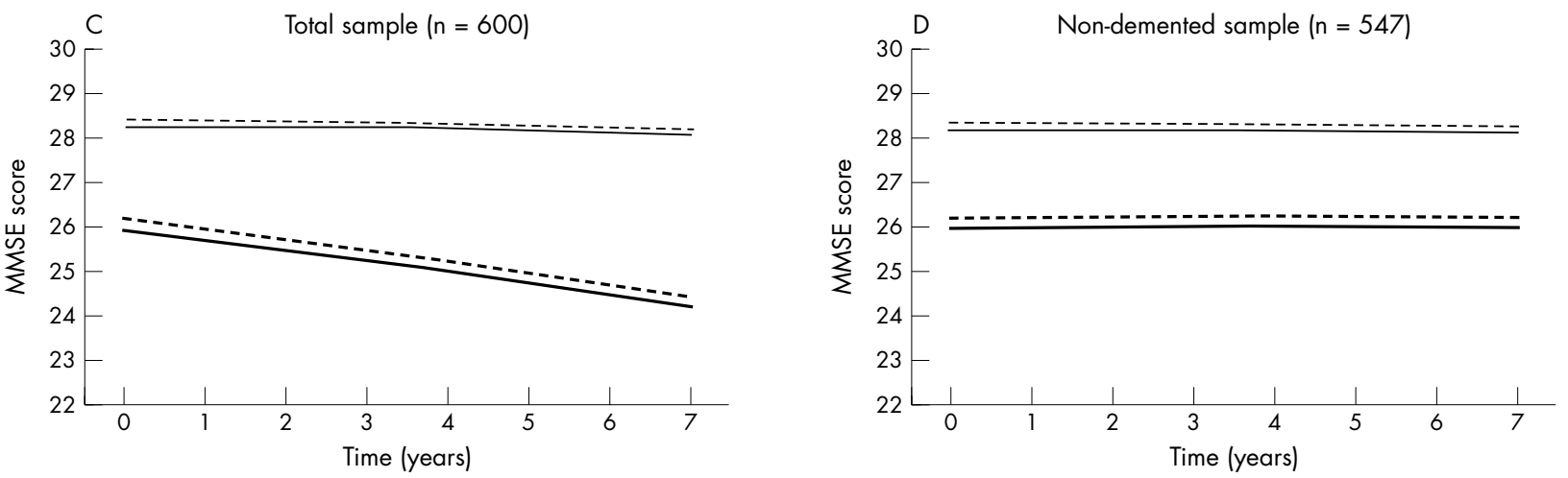

Figure 1 Graphical representation of the evolution of mean mini-mental state examination scores estimated by linear mixed effects models. Scores estimated are shown for all subjects $(A, C)$ and after exclusion of those diagnosed as demented during the 10 year follow up (B, D), before (A, B) and after (C, D) adjustment for education. ApoE, apolipoprotein E; MMSE, mini-mental state examination.

It is possible that certain genetic characteristics might influence both the level of education attained and any later susceptibility to cognitive change. apoE may influence cognitive function through direct changes in brain morphology in $\epsilon 4$ carriers, ${ }^{15}$ and it appears that the biological influence of the apoE genotype may be assessed by differences in cognitive function in clinically healthy people. Education could also exert a direct effect on cognition. Animal studies have shown that environmental experiences can modify brain anatomy and function. ${ }^{16}$ Swaab suggested that the activation of nerve cells in people who have completed higher education protects these cells from degeneration, thereby delaying the pathological process that lead to cognitive decline. ${ }^{17}$ Along the same lines, it was hypothesised that higher education could also lead to an increased brain reserve capacity, so that other neurones can take over the tasks of ones that have died. ${ }^{18}$

To some degree at least education may be a surrogate for other factors that could influence cognition. The educational classification used in our study was the attainment of a primary school diploma. This is based on linguistic and conceptual abilities, judged by performance in tests of reading, writing, and mathematical problem solving. The number of years of education were not not taken into account, only intellectual ability-subjects who fail the examination may subsequently be involved in less demanding cognitive tasks, leading to reduced brain stimulation and thus to a more limited cognitive reserve.
Our data suggest that apoE could play a direct role in cognition since early life by influencing the level of education that could be attained. In support of our data, two recent studies have shown a significant difference in the educational background between apoE $\epsilon 4$ carriers and non-carriers, the former staying in school longer than the latter. ${ }^{19}{ }^{20}$ The level of education could have a secondary influence on the brain reserve capacity.

A possible limitation of our study is whether the subcohort was a truly representative sample, as it was composed of volunteers from the French PAQUID cohort. However, the frequency of the individual apoE phenotypes observed in our sample was comparable with other published reports. ${ }^{6}$ The most important form of bias linked to longitudinal studies is cohort attrition. Dropout would have altered the results if it had affected the proportion of $\epsilon 4$ carriers, but in our study the proportion of $\epsilon 4$ carriers at baseline was not significantly different from the proportion at the end of the study.

Our results appeared to provide evidence for an influence of apoE on cognition, with decreased performance in $\epsilon 4$ carriers compared with $\epsilon 4$ non-carriers before the expression of dementing illness. However, this influence disappeared when adjusted for education. The evolution of cognitive performance in non-demented elderly people seems independent of the apoE phenotype. It remains to be established, however, whether the presence of the $\epsilon 4$ allele in combination with an inadequate cognitive performance is conclusive evidence for 
preclinical Alzheimer's disease. These aspects will be of particular interest for follow up studies.

\section{ACKNOWLEDGEMENTS}

The PAQUID project was funded by the following organisations: ARMA; Assurances SCOR; DANONE; Caisse Nationale d'Assurance Maladie des Travailleurs Salariés; Caisse Primaire d'Assurance Maladie de la Dordogne; Conseil Général de la Dordogne; Conseil Général de la Gironde; Conseil Régional d'Aquitaine; Direction Régionale des Affaires Sanitaires et Sociales d'Aquitaine; Fondation de France; INSERM; MGEN; Ministère de la Recherche et de la Technologie; Mutualité Sociale Agricole de la Dordogne; Mutualité Sociale Agricole de la Gironde; and NOVARTIS Pharma.

\section{Authors' affiliations}

M Winnock, L Letenneur, H Jacqmin-Gadda, J F Dartigues, INSERM U330, 146 rue Léo Saignat, 33076 Bordeaux cedex, France

J Dallongeville, P Amouyel, INSERM U508, Institut Pasteur de Lille, 59019 Lille cedex, France

Correspondence to: $\operatorname{Dr} \mathrm{L}$ Letenneur, INSERM U330, Université Victor Ségalen Bordeaux 2, 146 rue Léo Saignat, 33076 Bordeaux cedex, France; luc.letenneur@bordeaux.inserm.fr

Received 3 September 2001

In revised form 19 February 2002

Accepted 20 February 2002

\section{REFERENCES}

1 Strittmatter W, Saunders A, Schmechel D, et al. Apolipoprotein E: high avidity binding to beta-amyloid and increased frequency of type 4 allele in late-onset familial Alzheimer disease. Proc Natl Acad Sci USA 1993;90:1977-81

2 Sherrington R, Rogaev E, Liang $Y$, et al. Cloning of a gene bearing missense mutations in early-onset familial Alzheimer's disease. Nature 1995; 375:754-60

3 Poirier J, Davignon J, Bouthillier D, et al. Apolipoprotein E polymorphism and Alzheimer=s disease. Lancet 1993;342:697-9.

4 Strittmatter W, Roses A. Apolipoprotein E and Alzheimer disease. Proc Natl Acad Sci USA 1995;92:4725-7.
5 Saunders A. Strittmatter W, Schmechel D, et al. Association of apolipoprotein $\mathrm{E}$ allele epsilon 4 with late-onset familial Alzheimer disease. Neurology 1993;43:1467-72.

6 Farrer L, Cupples A, Haines J, et al. Effects of age, sex, and ethnicity on the association between apolipoprotein $\mathrm{E}$ genotype and Alzheimer disease. A meta-analysis. APOE and Alzheimer Disease Meta Analysis Consortium. JAMA 1997;278:1349-56.

7 Talbot C, Lendon C, Craddock N, et al. Protection against Alzheimer's disease with apoE epsilon 2. Lancet 1994;343:1432-3.

8 Folstein M, Folstein S, McHugh P. "Mini-mental state". A practical method for grading the cognitive state of patients for the clinician. $J$ Psychiatr Res 1975;12:189-98.

9 Jacqmin-Gadda H, Fabrigoule C, Commenges D, et al. A 5-year longitudinal study of the mini-mental state examination in normal aging Am J Epidemiol 1997; 145:498-506.

10 Morris JC, Edland S, Clark C, et al. The consortium to establish a registry for Alzheimer's disease (CERAD). Part IV. Rates of cognitive change in the longitudinal assessment of probable Alzheimer's disease. Neurology. 1993;43:2457-65.

11 Unger JM, van Belle G, Heyman A. Cross-sectional versus longitudinal estimates of cognitive change in non-demented older people: a CERAD study. Consortium to establish a registry for Alzheimer's disease. J Am Geriatr Soc 1999;47:559-63.

12 Dartigues J, Gagnon M, Barberger-Gateau P, et al. The PAQUID epidemiological program on brain aging. Neuroepidemiology 1992;11:14-18.

13 American Psychiatric Association. Diagnostic and statistical manual of mental disorders, 3rd ed, revised (DSM-III-R). Washington DC, American Psychiatric Association: 1987

14 Laird N, Ware J. Random-effects for longitudinal data. Biometrics 1982;38:963-74

15 Plassman B, Welsh-Bohmer K, Bigler E, et al. Apolipoprotein E epsilon 4 allele and hippocampal volume in twins with normal cognition. Neurology 1997;48:985-9

16 Diamond $M$, Bennett $E$, Lindner $B$, et al. Effects of environmental enrichment and impoverishment on rat cerebral cortex. J Neurobiol 1972;3:47-64.

17 Swaab D. Brain aging and Alzheimer's disease, "wear and tear" versus "use it or lose it". Neurobiol Aging 1991;12:317-24.

18 Katzman R. Education and the prevalence of dementia and Alzheimer's disease. Neurology 1993;43:13-20.

19 Codemo A, Corti M, Mazzetto G, et al. Education, APOE status and cognitive impairment in elderly. An epidemiological study in a rural setting. Neurobiol Aging 2000;21:S246.

20 Hubacek JA, Pitha J, Skodova Z, et al. A possible role of apolipoprotein E polymorphism in predisposition to higher education. Neuropsychobiology 2001;43:200-3.

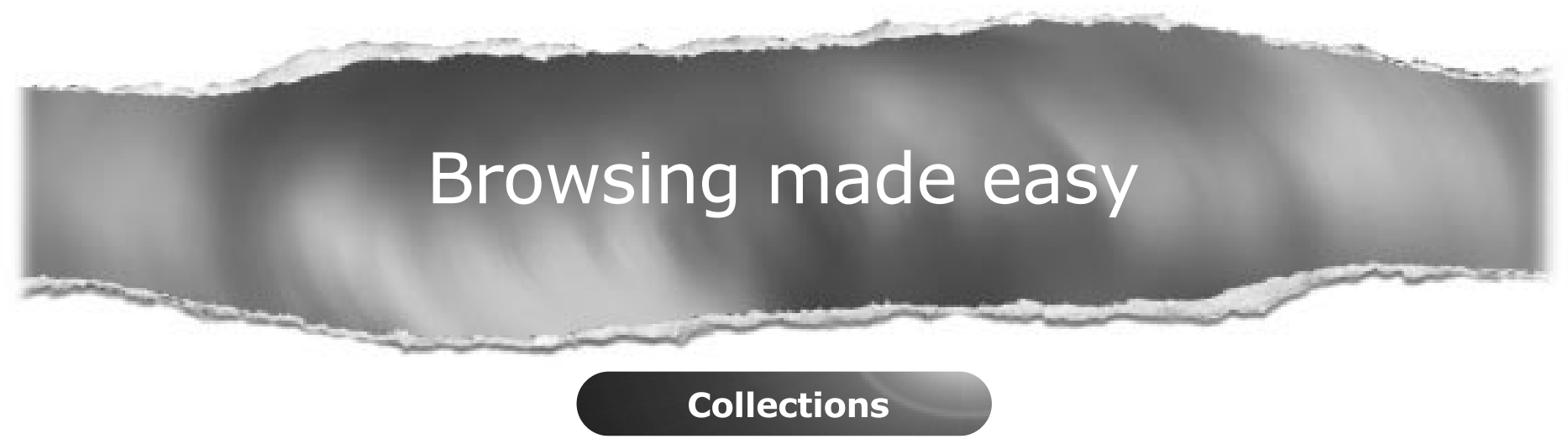

With a single click Collections allows you to find all articles that have been published in your chosen subject. Select from over 200 clinical and non-clinical topic collections and/or cross search other specialist journals, the BMJ and Cochrane Reviews

www.jnnp.com 